\title{
Basic health awareness and concerns prevalent among Indian hill farm women
}

\author{
VINEETA NAGARKOTI AND SUMAN PRASAD MAURYA
}

Received: 05.04.2014; Revised: 20.09.2014; Accepted: 01.10.2014

See end of the paper for authors' affiliations VINEETA NAGARKOTI

Department of Human Development and Family Studies, College of Home Science, G.B. Pant University of Agriculture and Technology, Pantnagar, UDHAM SINGH NAGAR

(UTTARAKHAND) INDIA Email: vineetanagarkoti@ gmail.com
ABSTRACT : Women have always been a part of the active work force in Uttarakhand, although their work remains unrecognized and formally unorganized. Health allied issues pertaining to women have always been a remarkable area for researchers and much has been explored. However, minimal research in this perspective has been conducted on women folk belonging to hilly regions. This paper is therefore, an attempt to unveil at least the basic health awareness and concerns prevalent among hill farm women. With ex-post facto research design the study was taken up in Dotiyal gaon of Takula block in Almora district. Sample size consisted of 50 hill farm women. Results signified poor health awareness and concerns among hill farm women, as in majority women were not aware about their blood group and the dietary differences of normal and pregnant women. They were suffering from different ailments as a result of their work culture. Concerted efforts by the medical community, government, NGOs and learned people willing to help is ardently entailed to create awareness and enlightening hill farm women for what is the basis of life i.e. health.

KEY WORDS: Basic health, Concerns prevalent, Indian hill farm women

- HOW TO CITE THIS PAPER : Nagarkoti, Vineeta and Maurya, Suman Prasad (2014). Basic health awareness and concerns prevalent among Indian hill farm women. Asian J. Home Sci., 9 (2) : 413-416. 